\title{
Andreae Vesalii Bruxellensis Icones anatomicae. Part I
}

The year 1543 saw the publication of two books which proved enormously influential. One was by a Pole, Niclas Koppernigk, the other by a Fleming, Andries van Wesel. Both authors are now much better known by the Latin versions of their names, Nicolas Copernicus and Andreas Vesalius. The books are De revolutionibus orbium cælestium, libri VI and De humani corporis fabrica libri septem, usually abbreviated to Fabrica. The ideas expounded by Copernicus changed how the universe was conceived. Though a claim of that magnitude is hardly conceivable for Vesalius's Fabrica, for many years it was taught that this book changed the study of human anatomy in all succeeding ages. There is no doubt that the Fabrica was a book that not only changed anatomical illustration forever but was also a new departure in the way in which it integrated text and illustration; it was also novel in its insistence (to a much greater extent than its predecessors) on the fundamental importance of direct observation. Recognition of these novel features has sometimes led to encomia that are more to be celebrated for their enthusiasm than their accuracy. For example, the anonymous leading article of the British Medical Journal (26 June 1943) celebrating the quatercentenary of the publication of the Fabrica ends:

The De humani corporis fabrica is a foundation work of modern biology and displaced the medieval view of the Microcosm, but its vast treasury of direct observation is set forth in a systematic and orderly fashion and in the full modern manner. If one took certain parts of it, correcting a few errors, it would read like a series of articles in a modern scientific journal. Thus it is fair to claim that it is not only a foundation work of modern science but also the first modern scientific book. In this additional sense it opens the modern period of science.

It would be difficult to defend the author's claims about the displacement of the view of the microcosm. Vesalius's prose reads nothing like a modern journal article; a modern scientific journal would not accept any article written in a style resembling that of Vesalius, and it is doubtful if any single book can really be said to 'open the modern period of science'. But it certainly contains a vast treasury of direct observation and it would be churlish to diminish the importance of this by over-insistence on those cases where Vesalius did not see fit to record what he must surely have seen - or, indeed, have seen to be absent. However, probably most of those authors whose enthusiasms we may not feel able to share would agree on the central importance of the illustrations to the force and influence of the work. And surely many more people have looked at the pictures than have read any of the text.

The Fabrica contains more than 200 woodcuts which are of quite remarkable quality. They combine astonishing anatomical detail with great clarity of execution and some of them - in particular the views of the skeleton and the illustrations of progressive dissection of the layers of muscle of the whole body (the 'musclemen') - are considerable works of art in their own right. We do not know for certain who the artist or artists responsible for drawing these remarkable illustrations were and their identity was the subject of acrimonious argument during much of the twentieth century. A seventeenth century attribution to Titian persisted intermittently and was only finally shown to be improbable to the point of impossibility in 2008.' On the other hand it does seem probable that the artist was one of Titian's circle and there is considerable evidence to point to the Netherlander, Jan Steven van Calcar as the artist of the drawings, or of many of them. Jan Steven worked in Titian's studio and was an acquaintance of the biographer of artists, sculptors and architects of the sixteenth century Giorgio Vasari who, in the second edition of his book (1568), explicitly attributes some of the images to Jan Steven:

In the same way as the eleven large plates on Anatomy made by Andrea Vesalio, and designed by Giovanni di Calcarea Fleming, most excellent painter, which were afterwards reproduced in small folio, and engraved in copper by Valverde, who wrote on Anatomy after Vesalio.

Kemp ${ }^{2}$ suggests that Vasari was referring here to the II images of the human figure in the Epitome rather than the 17 musclemen and skeletons of the Fabrica. For detailed discussion of the evidence for attribution to Jan 
Steven see Kemp and Guerra., ${ }^{2,3}$ Guerra also believes that the blockcutters were Francesco Marcolini (or Marcolino) da Forli and one of his workmen, a German, Johann Britt. Guerra's paper, in common with not a few others, uses the term 'engraver' to cover both cutters of woodblocks and engravers on copper and consistently refers to the illustrations as 'plates' which, in the case of the Fabrica is somewhat misleading. As Ivins, ${ }^{4}$ sometime curator of prints at the Metropolitan Museum in New York, pointed out in his combative but fascinating article of 1952, the image printed from a woodblock is a woodcut and that printed from a copper plate is a 'plate'. It should be noted, though, that Singer, O'Malley and Cushing, all of whom wrote extensively on Vesalius, utterly rejected the claim that Jan Steven van Calcar was the artist of the Fabrica. The reasons for their rejection of Jan Steven are ridiculed and dismissed by Ivins whose discussion, though aggressive, discourteous and not unprejudiced, is also quite convincing.

If the identity of the artist remains uncertain the quality of his work is not in question; indeed, in the images of the musclemen and skeletons, it amounts to genius. But the magnificence of the drawings would have amounted to nothing without the breathtaking skill of the block cutters who cut the images in relief on planks of pearwood sawn parallel to the grain. The sixteenthcentury blockcutters worked with a knife on the side of the plank and achieved astonishing results that were never surpassed. Indeed, after the end of the century, woodcuts were replaced by copper-plate engravings in all but the cheapest illustrated books and those woodcuts that were made for book illustration were poor in quality. Not till the end of the eighteenth century when Bewick devised his technique of engraving on the endgrain of boxwood blocks, a method completely different from that of the sixteenth-century wood block cutters, did book illustration again benefit from excellent woodcuts.

Astonishingly, most of the wood blocks for the Fabrica, cut in 1542 and in some cases modified for the second edition of 1555 , survived for 400 years; tragically they were destroyed in an Allied air raid on Munich in 1944. A summary of the wandering of the blocks from the sixteenth century and the story of their rediscovery in 1932 in a box in the library of the University of Munich is given by Willy Wiegand in his article of $1952 .{ }^{5}$

The New York Academy of Medicine in association with the Library of the University of Munich arranged for the Bremer Presse to print from the original sixteenthcentury wood blocks an edition of images which was issued in 1935 with a publication date of $1934 .^{6}$ The blocks for 227 of the original 289 images in the Fabrica and its companion volume the Epitome survived; photographic reproductions were added of the images whose blocks were lost and of Vesalius's earlier (1538)
Tabulae sex - the latter from one of the only two surviving copies of the work. The images from the blocks were printed using a modern hand-press under the direction of Dr Willy Wiegand, one of the founders of the Bremer Presse. The text of the figure legends was reprinted together with Vesalius's letter of 1542 to his printer in Basel, Oporinus, concerning the printing of the first edition of the Fabrica. However, the text of the Fabrica and Epitome was not reproduced. The block for the title-page of the I 543 Fabrica survived in Munich; the block for the second edition also survived (in Louvain) and it was lent to the publishers in Munich so that both title pages, each printed from its sixteenth-century wood block, could be included. They are printed facing each other and the differences in the quality of the composition of the anatomical scene are very obvious, the second edition being markedly inferior, as scholars have long claimed. The block cutting (it was probably cut in Basel for Oporinus for the second edition), though a fine piece of work, is not of the quality of the Venetian block of the first edition.

The Library has been fortunate in acquiring a copy of this, the last set of prints that were made from the sixteenth-century Vesalian blocks (and the last that will ever be made) in pristine condition with its pages as fresh as the day the sheets left the press. A reviewer of the book in 1938 feared that the paper which he felt was 'too white in contrast to the deep black ink which has been used in the reprinting' would soon begin to fox; more than 70 years later the paper is not at all foxed and is still startlingly white compared to that of the sixteenth-century pulls from the blocks to which we are accustomed. Though the Library is fortunate in having copies of both editions of the Fabrica (I543 and 1555), neither is complete; the title-page of the 1555 edition is missing and neither edition has the portrait of Vesalius. Nor do we have a copy of the first edition of the Epitome - the summary of the Fabrica that Vesalius published, also in 1543, principally for the use of students. Among many other important images, the Icones provides us with copies of these missing pictures and of the woodcuts of the Epitome.

\section{THE REPRINTING OF THE WOODCUTS IN 1934}

Willy Wiegand ${ }^{5}$ gives a fascinating account of the discovery of the blocks in Munich and of their remarkable condition; only a few small pieces had broken off during their travels. One can see examples of these small areas of loss in Figure I.The top couple of lines of the hills in the background have lost little pieces in the 1934 print. These lines are formed by isolated bands of wood, a fraction of a millimetre wide, carved out of the pearwood and standing unsupported; what is astonishing is not that there is a little loss of these fragile pieces but that so little has been lost. Wiegand points out that the 


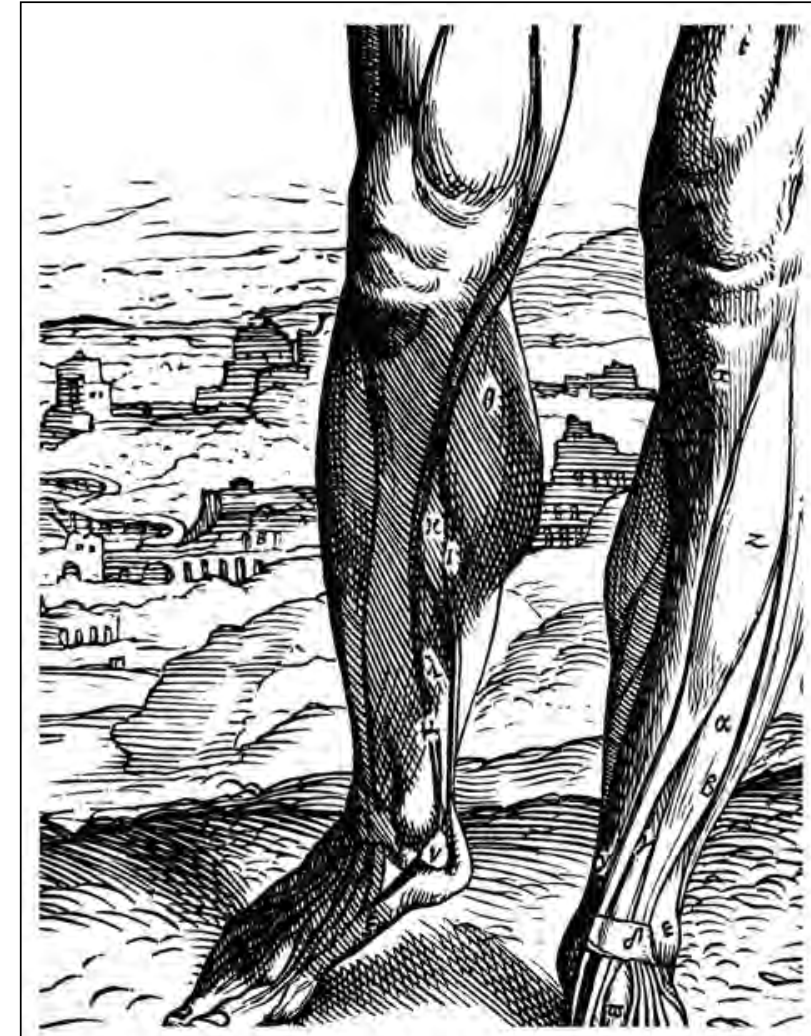

1934

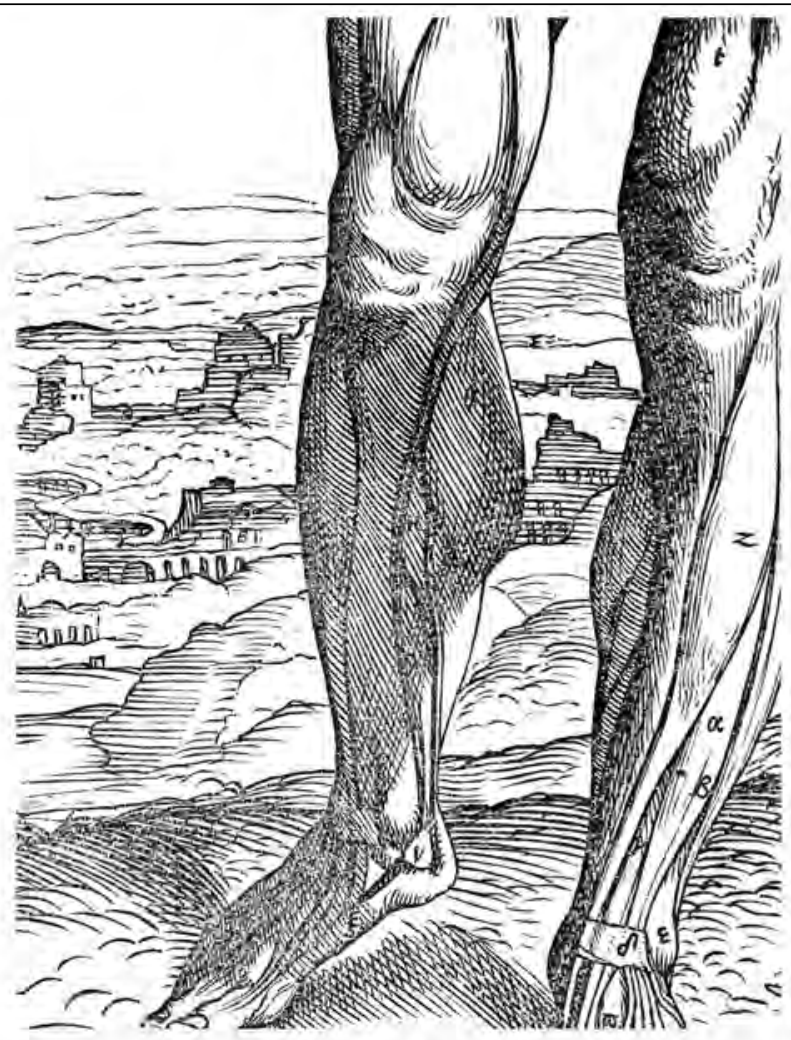

1543

FIGURE I Part of the first muscleman woodcut from (left) the Icones of 1934 and (right) the Fabrica of I543; both images were printed from the same woodblock. The block was reworked for the second edition of the Fabrica in I555 by cutting away parts of the shading to allow some label letters $(\theta \lambda \mu$ etc.) to be seen much more clearly. This is obvious in the 1934 print in which, also, the inking was heavier and greater clarity of line was achieved.

blocks had been treated with (perhaps boiled in) linseed oil before cutting and that the printing surfaces were remarkably flexible. Indeed, it is likely that it was this treatment with oil that enabled the blockcutters to achieve the seemingly impossible task of cutting such fine lines which sometimes cross the grain of the block.

Some of the blocks were altered for the 1555 edition and it is, of course, the re-worked form of the blocks which survived. The main changes were the removal of some hatching around index letters to make these much more easily visible. Some of the letters had been difficult to see or even effectively invisible in the 1543 edition. Figure I, comparing part of one of the musclemen in the Fabrica of 1543 and in the reprint of 1934 shows examples of this re-working.

The second part of this article will consider the reprints of the woodcuts from the Fabrica in more detail.

IML Donaldson, Honorary Librarian, RCPE (email: i.m.l.d@ed.ac.uk)

\section{NOTE}

tSee Wiegand ${ }^{5}$ for an illuminating discussion of the differences between the blocks of the title-pages of the I543 and I555 editions of the Fabrica.

\section{REFERENCES}

I Simons P, Kornell M.Annibal Caro's after-dinner speech (I536) and the question of Titian as Vesalius's illustrator. Renaissance Quarterly 2008; 61:1069-97.

2 Kemp M.A drawing for the Fabrica; and some thoughts upon the Vesalius muscle-men. Med Hist 1970; 14:277-88.

3 Guerra F. The identity of the artists involved in Vesalius's Fabrica 1543. Med Hist 1969; 13:37-50.

4 Ivins WM Jr. What about the Fabrica of Vesalius? In: Lambert SW, Wiegand W, Ivins WM Jr, editors. Three Vesalian essays to accompany the 'Icones Anatomicae' of 1934. New York: Macmillan; 1952. p. 43-127.

5 Wiegand W. Marginal notes by the printer of the Icones. In: Lambert SW,Wiegand W, Ivins WM Jr, editors. Three Vesalian essays to accompany the 'Icones Anatomicae' of 1934. New York: Macmillan; 1952. p. 27-42.

6 Vesalius A. Andreae Vesalii Bruxellensis Icones anatomicae. Munich Universitätsbibliothek München; New York: New York Academy of Medicine; 1934.

7 Ashley-Montagu MF.Andreae Vesalii bruxellensis Icones anatomicae Andreas Vesalius bruxellensis [book review]. Isis 1938; 28:467-9. 

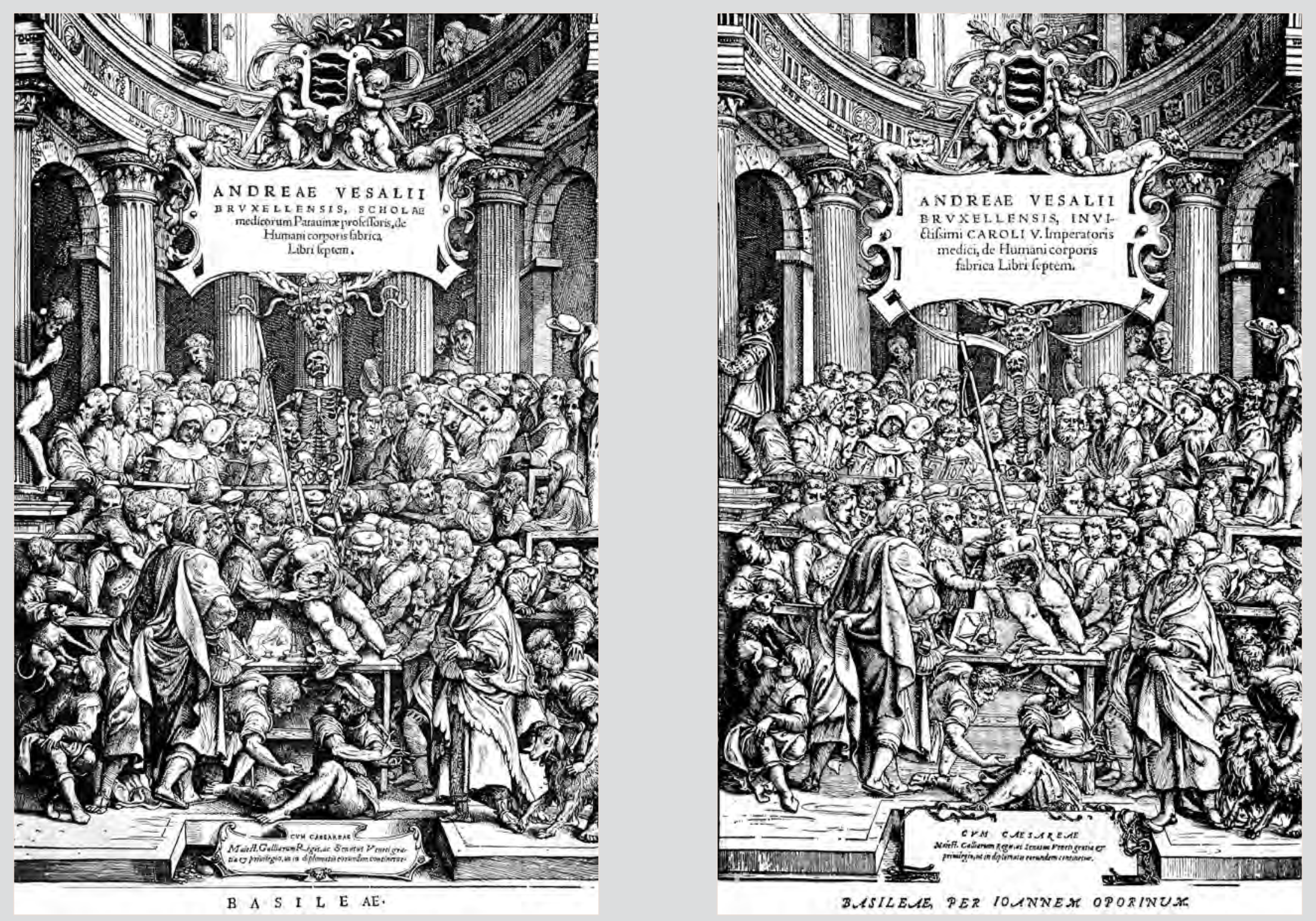

The title-pages of the two editions of Vesalius's Fabrica (left: 1543 and right: 1555) as reprinted from the original sixteenth century wood blocks in the Icones anatomicae of 1934. The block for the 1543 edition was cut in Venice in I542 for Vesalius; the block for the I555 edition was probably cut in Basel for the printer loannes Oporinus. See the article on pages 184-6 for more information. 